Article

\title{
Impact of Body Composition Status on 90-Day Mortality in Cancer Patients with Septic Shock: Sex Differences in the Skeletal Muscle Index
}

\author{
Youn-Jung Kim ${ }^{1, \dagger}{ }^{\text {, Dong-Woo Seo }}{ }^{1,2, \dagger}$, Jihoon Kang ${ }^{3}$, Jin Won Huh ${ }^{4}{ }^{\oplus}$, Kyung Won Kim ${ }^{5, *}$ and \\ Won Young $\operatorname{Kim}^{1, *(D)}$ \\ 1 Department of Emergency Medicine, University of Ulsan College of Medicine, Asan Medical Center, \\ Seoul 05505, Korea; yjkim.em@gmail.com (Y.-J.K.); leiseo@gmail.com (D.-W.S.) \\ 2 Department of Biomedical Informatics, University of California San Diego, School of Medicine, La Jolla, \\ CA 92093, USA \\ 3 Department of Hematology/Oncology, Department of Internal Medicine, Kangbuk Samsung Medical Center, \\ Sungkyunkwan University School of Medicine, Seoul 03181, Korea; jihoon_kang@hotmail.com \\ 4 Department of Pulmonary and Critical Care Medicine, University of Ulsan College of Medicine, \\ Asan Medical Center, Seoul 05505, Korea; jwhuh@amc.seoul.kr \\ 5 Department of Radiology, University of Ulsan College of Medicine, Asan Medical Center, Seoul 05505, Korea \\ * Correspondence: medimash@gmail.com or kyungwon_kim@amc.seoul.kr (K.W.K.); \\ wonpia73@naver.com (W.Y.K.); Tel.: +82-2-3010-4377 (K.W.K.); +82-2-3010-3350 (W.Y.K.) \\ + These authors contributed equally to this work.
}

Received: 22 August 2019; Accepted: 26 September 2019; Published: 2 October 2019

\begin{abstract}
Abnormalities in body composition are associated with poor prognosis in cancer patients. We investigated the association between body composition and 90-day mortality in cancer patients who developed septic shock. We included consecutive septic shock patients with active cancer from 2010 to 2017. The muscle area at the level of the third lumbar vertebra was measured by computed tomography upon emergency department admission and adjusted by height squared, yielding the Skeletal Muscle Index (SMI). Hazard ratios (HRs) and 95\% confidence intervals (CIs) for 90-day mortality were estimated using a Cox proportional hazards model. Among 478 patients, the prevalence of muscle depletion was $87.7 \%$. Among markers of body composition, the SMI only differed significantly between non-survivors and survivors (mean, $35.48 \mathrm{vs} .33 .32 \mathrm{~cm}^{2} / \mathrm{m}^{2} ; \mathrm{P}=0.002$ ) and was independently associated with lower 90-day mortality (adjusted HR, 0.970; $\mathrm{P}=0.001$ ). The multivariable-adjusted HRs ( $95 \%$ CI) for 90-day mortality comparing quartiles 2, 3, and 4 of the SMI to the lowest quartile were 0.646 (0.916-1.307), 0.620 (0.424-0.909), and $0.529(0.355-0.788)$, respectively. The associations were evident in male patients, but not in female patients. The SMI was independently associated with 90-day mortality in cancer patients with septic shock. The graded association between the SMI and 90-day mortality was observed in male patients.
\end{abstract}

Keywords: septic shock; neoplasms; prognosis; body composition; sarcopenia

\section{Introduction}

Recent advances in cancer treatment, including therapeutic interventions and supportive care, have improved the overall survival rates of patients with cancer [1]. The impairment of cellular and humoral immune systems due to cancer progression, therapeutic interventions such as chemo-radiationtherapy, and malnutrition are common in patients with cancer and increase vulnerabilities to infection, which can lead to rapid progression to sepsis and septic shock, a life-threatening or even fatal complication [2-5]. 
Recently, body composition in patients with cancer has been suggested as an important feature to predict the tolerance to therapeutic interventions as well as clinical outcomes, including survival and functional status before and during treatment [6-10]. Sarcopenia, defined as muscle depletion and decreased muscle function, is a reversible and preventable condition with adequate therapeutic interventions such as nutrition and physical rehabilitation [11]. Both tumor- and host-derived factors such as chronic inflammatory responses and a hypercatabolic state contribute to ongoing deterioration in patients with cancer and abnormalities of body composition have been suggested as another target requiring therapeutic intervention to improve survival and quality of life [12-14].

Several studies demonstrated the association between body composition, including muscle mass, sarcopenia, or visceral fat and mortality in patients with sepsis or in patients with cancer; however, the impact of body composition on the outcome of the patients with cancer who develop septic shock is not yet elucidated $[7,10,15-18]$. We hypothesized that body composition is a powerful prognostic factor for patients with cancer who develop septic shock. Thus, this study assessed the body composition status, including muscle area index, skeletal muscle attenuation, visceral/subcutaneous fat area, muscle depletion and obesity in cancer patients who presented to the emergency department (ED) with septic shock and evaluated the association between body composition and 90-day mortality.

\section{Materials and Methods}

\subsection{Study Design and Population}

The institutional review board of our hospital approved the registry (IRB number: 2015-1253), and informed consent was obtained before data collection. This observational, prospectively collected registry-based study was conducted at the ED of a tertiary-care university-affiliated hospital in Seoul, Korea, with an annual census of approximately 110,000 visits. Since 2010, all adult ( $\geq 18$ years) patients with suspected or confirmed infection and evidence of refractory hypotension or hypoperfusion at ED are enrolled in the septic shock registry of our center [19]. Refractory hypotension was defined as persistent hypotension (systolic blood pressure $<90 \mathrm{mmHg}$, a mean arterial pressure $<70 \mathrm{mmHg}$, or a systolic blood pressure decrease $>40 \mathrm{mmHg}$ ) after administering $\geq 20-30 \mathrm{~mL} / \mathrm{kg}$ intravenous fluid or requiring vasopressors to maintain a systolic blood pressure of $\geq 90 \mathrm{mmHg}$ or mean arterial pressure of $\geq 70 \mathrm{mmHg}$ [19]. Hypoperfusion was defined as a serum lactate level $\geq 4 \mathrm{mmol} / \mathrm{L}$ [20]. Patients were excluded in our septic shock registry if they refused admission to the intensive care unit and intensive treatment, signed a "do not attempt resuscitation" order, developed septic shock 6 or more hours after ED arrival, were transferred from other hospitals after stabilization, were directly transferred to other hospitals from the ED, or refused to enroll in the registry.

This study included patients with active solid cancer who were enrolled in the septic shock registry between January 2010 and December 2017 and who underwent abdominopelvic computed tomography (CT) examination at ED presentation. Active solid cancer was defined as a solid tumor which had been diagnosed or treated within the past 6 months, or with non-resectable and distant metastasis [21]. Patients were categorized into 90-day survivor and non-survivor groups. The institutional review board of our hospital approved this study (IRB number: 2019-0147) and waived the requirement for informed consent because the additional data were retrospectively retrieved from electronic medical records.

All patients were treated with sufficient crystalloid administration, with monitoring of volume status, acquisition of blood cultures before antibiotic administration, and administration of broad-spectrum antibiotics immediately after blood cultures and vasopressors in accordance with the then-current guidelines and bundles of the Surviving Sepsis Campaign [19]. Diagnostic work-up, including laboratory examination and computed tomography (CT) scans, were also performed in the ED. Patients were followed up until 90 days after hospital admission or the time of death. 


\subsection{Data Collection}

Data regarding age, sex, comorbid disease, focus of infection, sequential organ failure assessment (SOFA) score, and 90-day mortality were retrieved from the registry. SOFA score was calculated using the worst parameters during the initial $24 \mathrm{~h}$ after ED admission. The primary endpoint was 90-day mortality.

Additional data were collected for this study using the electronic medical records, including weight, height, type of solid cancer, and the presence of abdominopelvic CT scan to evaluate the body composition. We retrieved the data of body weight and height entered into the electronic health records at admission. The body composition, including skeletal muscle area (SMA), visceral fat area (VFA), and the subcutaneous fat area (SFA), was assessed at the L3 vertebral level of abdominopelvic CT scan performed at ED presentation. Abdominopelvic CT images extending from L3 in the inferior direction, which was performed at ED presentation, were assessed. An experienced radiologist (K.W.K) analyzed the $\mathrm{CT}$ images using AsanJ-Morphometry ${ }^{\mathrm{TM}}$ software. This dedicated software measures abdominal muscle and fat area based on Image (NIH, Bethesda, MD, USA) [22]. The SMA was demarcated using predetermined thresholds ( -29 to +190 Hounsfield units [HU]); the VFA and SFA were also demarcated using fat tissue thresholds ( -190 to $-30 \mathrm{HU}$ ) [23]. Skeletal muscle attenuation was assessed as the mean radiodensity in $\mathrm{HU}$ of all SMA at $\mathrm{L} 3$.

Body mass index (BMI) was calculated as the weight in kilograms divided by the height squared in meters $\left(\mathrm{kg} / \mathrm{m}^{2}\right)$. The Skeletal Muscle Index (SMI) was calculated as the SMA in $\mathrm{cm}^{2}$ divided by the height squared in meters $\left(\mathrm{cm}^{2} / \mathrm{m}^{2}\right)$ [7]. Obesity was defined as a BMI of $25 \mathrm{~kg} / \mathrm{m}^{2}$ or higher, which is the proposed cutoff for a diagnosis of obesity in Asians [24]. Sarcopenia, diagnosed based on the low muscle mass and impaired function, was defined using sex-specific SMIs [25]. Although the SMI cut-off values were proposed differently, we used sex-specific, BMI-dependent SMI cutoffs [7,18]. Sarcopenia was defined as $<43 \mathrm{~cm}^{2} / \mathrm{m}^{2}$ for a BMI $<25 \mathrm{~kg} / \mathrm{m}^{2},<53 \mathrm{~cm}^{2} / \mathrm{m}^{2}$ for a BMI of $25 \mathrm{~kg} / \mathrm{m}^{2}$ or more, and $<41 \mathrm{~cm}^{2} / \mathrm{m}^{2}$ regardless of the BMI for female patients in a previous study [18]. In addition, due to the lack of data about muscle strength or physical performance, we defined muscle depletion according to the previous sex-specific, BMI-dependent SMI cutoffs. Low skeletal muscle attenuation was defined as $<41 \mathrm{HU}$ for a BMI $<25 \mathrm{~kg} / \mathrm{m}^{2}$ and $<33 \mathrm{HU}$ for a BMI of $25 \mathrm{~kg} / \mathrm{m}^{2}$ or more [18].

\subsection{Statistical Analysis}

Descriptive statistics were used to summarize the characteristics of the study patients according to 90-day mortality and according to the presence of muscle depletion. Continuous variables are presented as means (standard deviation, SD) or medians (interquartile range, IQR) according to their distribution per the Kolmogorov-Smirnov test. Categorical variables are presented as absolute numbers (percentage). Sex-specific SMIs were grouped into quartiles based on the distribution within the study patients as follows: $<31.03,31.03-36.45,36.46-42.06$, and $>42.06 \mathrm{~kg} / \mathrm{m}^{2}$ for male and $<27.22$, $27.22-31.35,31.36-35.47$, and $>35.47 \mathrm{~kg} / \mathrm{m}^{2}$ for female patients. Additionally, odds ratios (ORs) and $95 \%$ confidence intervals (CIs) for the presence of muscle depletion were examined using univariable and multivariable logistic regression analysis. Variables were tested for goodness of fit using variable methods such as the Hosmer-Lemeshow test and Stukel test.

The primary endpoint was all-cause 90-day mortality. Each participant was followed from ED admission until either death or 90 days after ED admission, whichever occurred first. Hazard ratios (HRs) and 95\% CIs for 90-day mortality were estimated using Cox proportional hazards regression analyses. The model was adjusted for age, sex, and other variables that might affect 90-day mortality: hypertension, diabetes mellitus, type of solid cancer, focus of infection, SOFA score at admission, the SMI and skeletal muscle attenuation. The proportional hazards assumption was assessed by examining graphs of the estimated log minus log plots and no violation of the assumption was found. We also evaluated the association between the SMI and 90-day mortality separately in female and male patients. Survival in the sex-specific SMI quartiles was assessed by nonparametric Kaplan-Meier survival analysis and compared by log-rank tests. Two-tailed P-values less than 0.05 were considered 
statistically significant. All statistical analyses were performed using IBM SPSS Statistics for Windows, version 20.0 (IBM Corp., Armonk, NY, USA).

\section{Results}

During the study period, a total of 2425 patients with septic shock were enrolled in the septic shock registry and $478(19.7 \%)$ patients with active solid cancer were finally included. Among these 478 patients, 208 (43.5\%) died within 90 days (Figure 1).

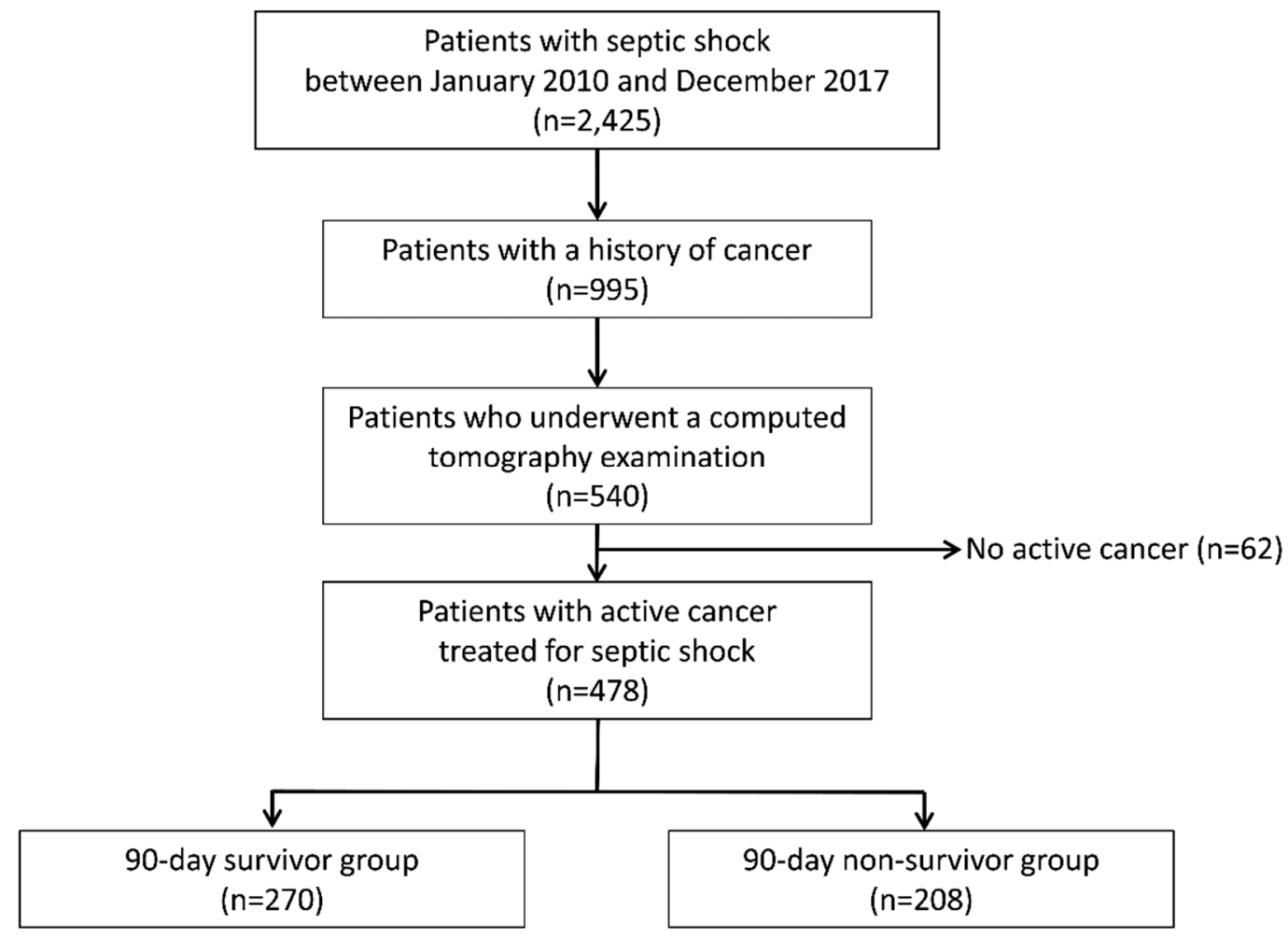

Figure 1. Flow diagram of patient enrolment and allocation in our study.

The demographic and clinical characteristics of the patients are presented in Table 1 . The median age of our study patients was 65.0 (IQR, 58.0-72.0) years and $62.1 \%$ of the patients were males. Hepatobiliary cancer $(51.7 \%)$ was the most frequent cancer type, followed by gastrointestinal cancer $(19.0 \%)$, gynecologic cancer $(10.0 \%)$, lung cancer $(6.5 \%)$, and others $(12.8 \%)$. The focus of infection significantly differed between the survivor and non-survivor groups. No significant difference in SOFA score was observed between the survivor and non-survivor groups (median, 7.0 vs. $7.0, \mathrm{P}=0.225$ ).

The body compositions in the overall patient population and by sex are presented in Table 2. Muscle depletion was predominant in the overall patient population $(87.7 \%)$ and did not differ significantly between the survivor and non-survivor groups. Low skeletal muscle attenuation was observed in $42.3 \%$ of the patients with statistical difference between the survivor and non-survivor groups $(37.8 \%$ vs. $48.1 \%, \mathrm{P}=0.024)$. The SMIs were significantly higher in survivors compared to that in non-survivors in patients overall (mean, 35.48 vs. $33.32 \mathrm{~cm}^{2} / \mathrm{m}^{2}, \mathrm{P}=0.002$ ) and in male patients (mean, 37.55 vs. $35.18 \mathrm{~cm}^{2} / \mathrm{m}^{2}, \mathrm{P}=0.008$ ); however, no significant difference was observed in female patients (mean, 31.91 vs. $30.45 \mathrm{~cm}^{2} / \mathrm{m}^{2}, \mathrm{P}=0.116$ ). Similarly, the skeletal muscle attenuation was significantly higher in survivors compared to that in non-survivors in patients overall (mean, 35.40 vs. $33.36 \mathrm{HU}, \mathrm{P}=0.001$ ) and in male patients (mean, 37.51 vs. $34.72 \mathrm{HU}, \mathrm{P}<0.001$ ); however, no significant difference was observed in female patients (mean, 31.73 vs. $31.27 \mathrm{HU}, \mathrm{P}=0.613$ ). The clinical characteristics and body composition of the patients with and without muscle depletion are summarized in Table S1. Patients with muscle depletion were significantly older (median, $66.0 \mathrm{vs.}$ 
62.0 years; $\mathrm{P}=0.003$ ), more frequently female (male, $58.9 \%$ vs. $84.7 \% ; \mathrm{P}<0.001$ ) and had a lower BMI (median, 21.8 vs. $22.8 \mathrm{~kg} / \mathrm{m}^{2} ; \mathrm{P}=0.029$ ) and skeletal muscle attenuation (mean, 33.80 vs. $39.54 \mathrm{HU}$; $\mathrm{P}<0.001$ ). In multivariable logistic regression analysis, age (adjusted OR, 1.041; 95\% CI, 1.012-1.070; $\mathrm{P}=0.006$ ), male sex (adjusted OR, 0.277; 95\% CI, 0.128-0.600; $\mathrm{P}=0.001$ ) and low skeletal muscle attenuation (adjusted OR, 7.454; 95\% CI, 2.891-19.219; P < 0.001) were significantly associated with the muscle depletion in cancer patients with septic shock (Table S2).

Table 1. Demographic and clinical characteristics of study patients according to 90-day mortality.

\begin{tabular}{|c|c|c|c|c|}
\hline Characteristics & Overall patients $(n=478)$ & Survivors $(n=270)$ & Non-survivors $(n=208)$ & P-Value \\
\hline Age, years & $65.0(58.0-72.0)$ & $65.0(58.0-72.0)$ & $65.0(58.0-72.0)$ & 0.848 \\
\hline Male & $297(62.1 \%)$ & $171(63.3 \%)$ & $126(60.6 \%)$ & 0.538 \\
\hline \multicolumn{5}{|l|}{ Comorbidities } \\
\hline Hypertension & $169(35.4 \%)$ & $94(34.8 \%)$ & $75(36.1 \%)$ & 0.778 \\
\hline Diabetes mellitus & $124(25.9 \%)$ & $71(26.3 \%)$ & $53(25.5 \%)$ & 0.840 \\
\hline Type of solid cancer & & & & 0.219 \\
\hline Hepatobiliary & $247(51.7 \%)$ & $137(50.7 \%)$ & $110(52.9 \%)$ & \\
\hline Gastrointestinal & $91(19.0 \%)$ & $52(19.3 \%)$ & $39(18.8 \%)$ & \\
\hline Gynecologic & $48(10.0 \%)$ & $33(12.2 \%)$ & $15(7.2 \%)$ & \\
\hline Lung & $31(6.5 \%)$ & $13(4.8 \%)$ & $18(8.7 \%)$ & \\
\hline Others & $61(12.8 \%)$ & $35(13.0 \%)$ & $26(12.5 \%)$ & \\
\hline Focus of infection & & & & 0.029 \\
\hline Hepatobiliary & $243(50.8 \%)$ & $136(50.4 \%)$ & $107(51.4 \%)$ & \\
\hline Respiratory & $63(13.2 \%)$ & $27(10.0 \%)$ & $36(17.3 \%)$ & \\
\hline Others & $172(36.0 \%)$ & $107(39.6 \%)$ & $65(31.3 \%)$ & \\
\hline SOFA score & $7.0(5.0-10.0)$ & $7.0(5.0-9.0)$ & $7.0(5.0-10.0)$ & 0.225 \\
\hline
\end{tabular}

Data are presented as median (interquartile range), and number (percentage). Abbreviations: SOFA, Sequential Organ Failure Assessment.

Table 2. Body composition of study patients by sex and 90-day mortality.

\begin{tabular}{|c|c|c|c|c|}
\hline Body Composition & Overall & Survivors & Non-Survivors & P-Value \\
\hline \multicolumn{5}{|l|}{ Overall patients } \\
\hline Number & 478 & 270 & 208 & \\
\hline BMI, $\mathrm{kg} / \mathrm{m}^{2}$ & $22.0(19.6-24.3)$ & $22.1(20.0-24.4)$ & $21.7(19.4-24.1)$ & 0.292 \\
\hline SFA, $\mathrm{cm}^{2}$ & $89.40(53.71-144.18)$ & $95.14(59.25-148.25)$ & $85.35(49.35-140.31)$ & 0.154 \\
\hline VFA, $\mathrm{cm}^{2}$ & $95.29(56.96-134.44)$ & $100.06(58.06-140.23)$ & $89.78(54.16-128.66)$ & 0.212 \\
\hline $\mathrm{SMA}, \mathrm{cm}^{2}$ & $89.64(73.46-107.68)$ & $93.32(76.67-111.42)$ & $84.88(71.23-102.26)$ & 0.002 \\
\hline $\mathrm{SMI}, \mathrm{cm}^{2} / \mathrm{m}^{2}$ & $34.54(7.58)$ & $35.48(7.54)$ & $33.32(7.48)$ & 0.002 \\
\hline Skeletal muscle attenuation, $\mathrm{HU}$ & $34.51(6.94)$ & $35.40(6.76)$ & $33.36(7.00)$ & 0.001 \\
\hline VFA/SFA ratio & $1.07(0.72-1.67)$ & $1.04(0.69-1.61)$ & $1.13(0.73-1.73)$ & 0.306 \\
\hline Obesity & $90(18.8 \%)$ & $50(18.5 \%)$ & $40(19.2 \%)$ & 0.843 \\
\hline Muscle depletion & $419(87.7 \%)$ & $231(85.6 \%)$ & $188(90.4 \%)$ & 0.112 \\
\hline Low skeletal muscle attenuation & $202(42.3 \%)$ & $102(37.8 \%)$ & $100(48.1 \%)$ & 0.024 \\
\hline $\begin{array}{c}\text { Male } \\
\text { Number }\end{array}$ & 297 & 171 & 126 & \\
\hline $\mathrm{BMI}, \mathrm{kg} / \mathrm{m}^{2}$ & $21.8(19.4-23.8)$ & $21.9(19.5-23.7)$ & $21.3(19.1-23.9)$ & 0.401 \\
\hline $\mathrm{SFA}, \mathrm{cm}^{2}$ & $73.65(44.88-118.68)$ & $78.03(51.38-118.13)$ & $67.90(36.83-119.54)$ & 0.133 \\
\hline VFA, $\mathrm{cm}^{2}$ & $100.49(55.09-148.09)$ & $105.23(57.61-152.68)$ & $95.75(53.24-143.99)$ & 0.573 \\
\hline $\mathrm{SMA}, \mathrm{cm}^{2}$ & $99.51(85.99-115.74)$ & $106.01(90.99-118.78)$ & $93.12(82.32-110.71)$ & 0.002 \\
\hline SMI, $\mathrm{cm}^{2} / \mathrm{m}^{2}$ & $36.55(7.64)$ & $37.55(7.40)$ & $35.18(7.79)$ & 0.008 \\
\hline Skeletal muscle attenuation, $\mathrm{HU}$ & $36.33(6.75)$ & $37.51(6.08)$ & $34.72(7.30)$ & $<0.001$ \\
\hline VFA/SFA ratio & $1.33(1.00-1.96)$ & $1.30(0.93-1.93)$ & $1.42(1.07-2.03)$ & 0.083 \\
\hline Obesity & $45(15.2 \%)$ & $24(14.0 \%)$ & $21(16.7 \%)$ & 0.532 \\
\hline Muscle depletion & $247(83.2 \%)$ & $138(80.7 \%)$ & $109(86.5 \%)$ & 0.186 \\
\hline Low skeletal muscle attenuation & $105(35.4 \%)$ & $51(29.8 \%)$ & $54(42.9 \%)$ & 0.020 \\
\hline \multicolumn{5}{|l|}{ Female } \\
\hline Number & 181 & 99 & 82 & \\
\hline BMI, $\mathrm{kg} / \mathrm{m}^{2}$ & $22.8(3.9)$ & $23.0(4.0)$ & $22.6(3.8)$ & 0.496 \\
\hline $\mathrm{SFA}, \mathrm{cm}^{2}$ & $132.92(75.82)$ & $137.64(75.26)$ & $127.22(76.57)$ & 0.359 \\
\hline VFA, $\mathrm{cm}^{2}$ & $92.93(49.68)$ & $97.95(54.30)$ & $86.85(42.99)$ & 0.135 \\
\hline
\end{tabular}


Table 2. Cont.

\begin{tabular}{|c|c|c|c|c|}
\hline $\mathrm{SMA}, \mathrm{cm}^{2}$ & $74.27(15.61)$ & $75.66(15.47)$ & $72.59(15.72)$ & 0.190 \\
\hline SMI, $\mathrm{cm}^{2} / \mathrm{m}^{2}$ & $31.25(6.21)$ & $31.91(6.37)$ & $30.45(5.96)$ & 0.116 \\
\hline Skeletal muscle attenuation, HU & $31.52(6.17)$ & $31.73(6.33)$ & $31.27(5.99)$ & 0.613 \\
\hline VFA/SFA ratio & $0.74(0.52-0.96)$ & $0.75(0.52-1.00)$ & $0.74(0.51-0.95)$ & 0.782 \\
\hline Obesity & $45(24.9 \%)$ & $26(26.3 \%)$ & $19(23.2 \%)$ & 0.632 \\
\hline Muscle depletion & $172(95.0 \%)$ & $93(93.9 \%)$ & $79(96.3 \%)$ & 0.515 \\
\hline Low skeletal muscle attenuation & $97(53.6 \%)$ & $51(51.5 \%)$ & $46(56.1 \%)$ & 0.538 \\
\hline
\end{tabular}

In the univariate analysis, the following covariates were significantly associated with 90-day mortality: focus of infection, which was categorized into hepatobiliary, respiratory, and others; SOFA score; SMI; and low skeletal muscle attenuation (Table S3). Multivariable Cox proportional hazards regression analyses showed that the SMI was independently associated with a lower 90-day mortality (adjusted HR, 0.970; 95\% CI, 0.952-0.988; P = 0.001), whereas the presence of low skeletal muscle attenuation was not. For further analysis, the SMI was grouped into quartiles by sex. The multivariable-adjusted HR (95\% CI) for 90-day mortality comparing quartiles 2, 3, and 4 of the SMI to the lowest quartile were $0.958(0.667-1.376), 0.644(0.438-0.946)$, and 0.559 (0.373-0.837), respectively (Table 3). A negative association between the SMI quartile and 90-day mortality was consistently observed in male patients, whereas the SMI quartile was not significantly associated with 90-day mortality in female patients. Overall patients and male patients with the SMIs in the first and second quartiles had a significantly shorter survival duration compared to those in overall and male patients with the SMIs in the third and fourth quartiles (Figure 2A,B). However, no significant differences between the SMI quartiles were observed among female patients ( $P=0.257$ by log-rank test; Figure $2 \mathrm{C}$ ).

Table 3. Hazard ratios for 90-day mortality by muscle area index quartile in study participants.

\begin{tabular}{|c|c|c|c|c|}
\hline Population & HR $(95 \%$ CI $)$ & P-Value & $\begin{array}{c}\text { Multivariable-Adjusted HR } \\
\text { (95\% CI) }\end{array}$ & P-Value \\
\hline \multicolumn{5}{|l|}{ Overall population } \\
\hline $\mathrm{Q} 1$ & Reference & & Reference & \\
\hline$\widehat{\mathrm{Q}} 2$ & $0.920(0.645-1.312)$ & 0.646 & $0.958(0.667-1.376)$ & 0.817 \\
\hline Q3 & $0.620(0.423-0.908)$ & 0.014 & $0.644(0.438-0.946)$ & 0.025 \\
\hline Q4 & $0.539(0.362-0.802)$ & 0.002 & $0.559(0.373-0.837)$ & 0.005 \\
\hline \multicolumn{5}{|l|}{ Male } \\
\hline Q1 $(<31.03)$ & Reference & & Reference & \\
\hline Q2 (31.03-36.45) & $0.894(0.570-1.402)$ & 0.627 & $0.950(0.598-1.511)$ & 0.829 \\
\hline Q3 (36.46-42.06) & $0.527(0.319-0.871)$ & 0.012 & $0.539(0.324-0.895)$ & 0.017 \\
\hline $\mathrm{Q} 4(>42.06)$ & $0.534(0.323-0.883)$ & 0.014 & $0.577(0.344-0.967)$ & 0.037 \\
\hline \multicolumn{5}{|l|}{ Female } \\
\hline Q1 (<27.22) & Reference & & Reference & \\
\hline Q2 (27.22-31.35) & $0.970(0.544-1.729)$ & 0.917 & $0.840(0.452-1.561)$ & 0.581 \\
\hline Q3 (31.36-35.47) & $0.787(0.435-1.421)$ & 0.426 & $0.614(0.314-1.199)$ & 0.153 \\
\hline $\mathrm{Q} 4(>35.47)$ & $0.549(0.286-1.053)$ & 0.071 & $0.418(0.204-0.856)$ & 0.017 \\
\hline
\end{tabular}

The multivariable model was adjusted for age, sex, hypertension, diabetes mellitus, type of solid cancer (hepatobiliary, gastrointestinal, gynecologic, lung, and others), focus of infection (hepatobiliary, respiratory, and others), and Sequential Organ Failure Assessment score at admission. Abbreviations: HR, hazard ratio; CI, confidence interval; $Q$, quartile. 

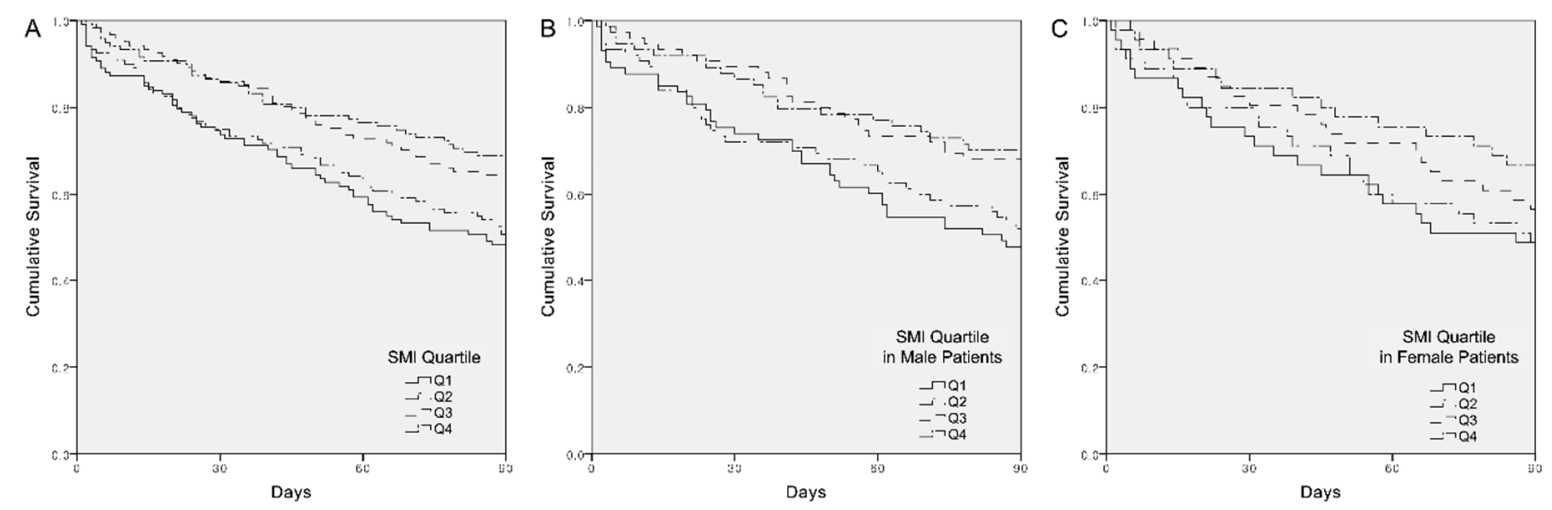

Figure 2. Kaplan-Meier survival curve estimates of 90-day mortality in (A) overall, (B) male, and (C) female patients according to their skeletal muscle index (SMI) quartiles.

\section{Discussion}

In this registry-based cohort study, we found that muscle depletion was prevalent and that an increased SMI was associated with reduced 90-day mortality in patients with cancer who developed septic shock. The cancer patients had a higher overall prevalence of sarcopenia due to metabolic alterations such as anorexia, hypoanabolism, or hypercatabolism, which might elicit dramatic changes in body composition $[26,27]$. A recent systemic review reported that the overall prevalence of pre-therapeutic sarcopenia in cancer patients was $40 \%$, ranging from $12 \%$ in colorectal cancer to $80 \%$ in esophageal cancer [6]. Moreover, patients with sepsis often experience muscle catabolism, muscle weakness, and metabolic dysfunction. Active cancer patients with septic shock can explain the high overall prevalence of muscle depletion $(87 \%)$, which consisted of pre-sarcopenia and sarcopenia, in our study. Our result is consistent with that of a previous study reporting that the progression of muscle depletion contributed to the development of septic shock in cancer patients. Undernutrition impairs host immune function, especially cell-mediated immunity, including T-lymphocytes, complement activity, phagocytosis, and chemotaxis [28]. When systemic inflammation is accompanied by this state, immune function is further depressed and the patient consequently develops septic shock, a dysregulated response to an infection [28].

The severity of sarcopenia has been shown to be both a marker for overall patient health status and a predictor of patient outcomes $[16,29,30]$. This is consistent with the findings of the present study. Compared to the lowest quartile of the SMI, higher quartiles of the SMI (third and fourth) were independently associated with a decreased 90-day mortality among the study patients, especially for male patients, after adjusting for other possible confounding factors.

Body composition and metabolism of fat and protein differ between men and women; however, few studies have assessed the impact of sex differences in body composition on survival in patients with cancer [31-33]. Therefore, we analyzed the body composition of our patients by sex. In male patients, the SMA, SMI and skeletal muscle attenuation were significantly higher in survivors than those in non-survivors and the VFA/SFA ratio tended to be lower in survivors than that in non-survivors, although the difference was not statistically significant. In contrast to male patients, body composition, including the SMA, SFA, VFA, and skeletal muscle attenuation, did not differ between survivors and non-survivors in female patients. In overall patients, the SMI was an independent predictor of a lower 90-day mortality after adjusting for other variables that might affect 90-day mortality in septic shock (adjusted HR, 0.970; 95\% CI, 0.952-0.988; $\mathrm{P}=0.001$ ). However, the association of muscle depletion and 90-day mortality was evident in male but not female patients.

Sex-based differences have been widely reported for skeletal muscle fiber-type composition, function, and muscle fatigue susceptibility in preclinical models and healthy participants [34,35]. Cancer-induced muscle wasting causes atrophy in type II glycolytic fibers rather than in type I oxidative myofibers [36], and type II glycolytic fibers account for a greater percentage of muscle composition in men than in women [34,37]. Also, men are more susceptible than women to muscle 
fatigue and this functional impairment was more obvious in male cancer patients than in females [38]. The mechanism of this sexual dimorphism is not yet elucidated despite the acknowledged roles of estrogen and androgen in muscle mass and function [32]. In our real-world study, the prognostic value of body composition, particularly the SMI, differed between male and female patients. Consistent with our findings, Choi et al. also reported that the association between muscle depletion and mortality was more prominent in male compared to female patients with advanced pancreatic cancer [39]. These results imply that muscle depletion, sarcopenia, and cancer cachexia have different progression and prognostic impacts for male and female patients and that prevention and treatment strategies for these pathologic conditions may need to be developed based on the understanding of the properties these sexual dimorphisms [32].

Several limitations should be considered when interpreting the findings of the present study. First, a lack of data regarding more specific cancer-related characteristics such as cancer stage, performance status, and treatment trajectory was a significant limitation. Also, our primary outcome was all-cause 90-day mortality, which did not differentiate causes of mortality, including cancer and septic shock. However, recent studies demonstrated that cancer-related characteristics were not associated with short-term mortality $[40,41]$, and the septic shock registry of our institution excludes patients who refused admission to the intensive care unit and intensive treatment or who signed a "do not attempt resuscitation" order. Considering these exclusion criteria of the septic shock registry, our study patients might have good performance status with a life expectancy of more than three months due to cancer. Second, the treatment of septic shock and cancer differ owing to the long study period accompanied by changes in treatment guidelines. In-hospital treatment strategies such as ventilator use or continuous renal replacement therapy as well as end-of-life decisions could affect the outcome. These potential confounding factors were not standardized between attending physicians. Third, we evaluated the patients using only a measurement of muscle mass adjusted by height squared. The impairment of muscle strength or physical performance such as gait speed and hand-grip strength is another key aspect in patients with sarcopenia and cachexia [11]; however, these data were not available due to the retrospective nature of this cohort study. Finally, this study was performed at the ED of single tertiary referral center in South Korea and all study patients were Asians, which compromises the generalizability of the findings. Race-ethnic differences in body composition have been generally reported [42]; our study adds data on body composition in Asian patients with cancer who developed septic shock. Also, this study included cancer patients with septic shock who underwent an abdominopelvic CT examination at ED presentation. The results of this study were only generalizable to those patients who needed an abdominopelvic $\mathrm{CT}$ examination at presentation and cannot be extended to all cancer patients with septic shock.

\section{Conclusions}

In conclusion, in the present study, most patients with cancer who developed septic shock had muscle depletion, which was independently associated with 90-day mortality in patients overall. Only in male patients was a graded association observed between the SMI and 90-day survival. Our results suggest that sex differences should be considered to establish better prognostication and treatment strategies. Further prospective validation studies in this population are warranted.

Supplementary Materials: The following are available online at http://www.mdpi.com/2077-0383/8/10/1583/s1: Table S1, Demographic and clinical characteristics of study patients with and without muscle depletion; Table S2, Odds ratios for muscle depletion by logistic regression analysis in patients with cancer who developed septic shock; Table S3, Hazard ratios for 90-day mortality by Cox proportional hazards analysis in patients with cancer who developed septic shock.

Author Contributions: Conceptualization, Y.-J.K., D.-W.S., and W.Y.K.; methodology, Y.-J.K., D.-W.S., K.W.K. and W.Y.K.; formal analysis, Y.-J.K. and D.-W.S.; investigation, all authors; resources, Y.-J.K., D.-W.S., K.W.K. and W.Y.K.; data curation, Y.-J.K.; writing (original draft), Y.-J.K.; writing (review and editing), all authors; visualization, Y.-J.K.; supervision, W.Y.K.; project administration, Y.-J.K., D.-W.S. and W.Y.K. 
Funding: This work was supported by a grant from the National Research Foundation of Korea (NRF-2018R1D1A1B07050136).

Conflicts of Interest: The authors declare that they have no competing interests.

\section{References}

1. Puxty, K.; McLoone, P.; Quasim, T.; Sloan, B.; Kinsella, J.; Morrison, D.S. Risk of critical illness among patients with solid cancers: A population-based observational study. JAMA Oncol. 2015, 1, 1078-1085. [CrossRef] [PubMed]

2. Legrand, M.; Max, A.; Peigne, V.; Mariotte, E.; Canet, E.; Debrumetz, A.; Lemiale, V.; Seguin, A.; Darmon, M.; Schlemmer, B. Survival in neutropenic patients with severe sepsis or septic shock. Crit. Care Med. 2012, 40, 43-49. [CrossRef] [PubMed]

3. Williams, M.D.; Braun, L.A.; Cooper, L.M.; Johnston, J.; Weiss, R.V.; Qualy, R.L.; Linde-Zwirble, W. Hospitalized cancer patients with severe sepsis: Analysis of incidence, mortality, and associated costs of care. Crit. Care 2004, 8, R291. [CrossRef] [PubMed]

4. Kim, Y.-J.; Jung, S.M.; Kang, J.; Ryoo, S.M.; Sohn, C.H.; Seo, D.-W.; Lim, K.S.; Huh, J.W.; Kim, S.-H.; Kim, W.Y. Risk factors for extended-spectrum beta-lactamase-producing Enterobacteriaceae infection causing septic shock in cancer patients with chemotherapy-induced febrile neutropenia. Intern. Emerg. Med. 2019, 14, 433-440. [CrossRef] [PubMed]

5. Kim, Y.-J.; Kang, J.; Ryoo, S.M.; Ahn, S.; Huh, J.W.; Kim, W.Y. Platelet-Lymphocyte Ratio after Granulocyte Colony Stimulating Factor Administration: An Early Prognostic Marker in Septic Shock Patients with Chemotherapy-Induced Febrile Neutropenia. Shock 2019, 52, 160-165. [CrossRef] [PubMed]

6. Pamoukdjian, F.; Bouillet, T.; Lévy, V.; Soussan, M.; Zelek, L.; Paillaud, E. Prevalence and predictive value of pre-therapeutic sarcopenia in cancer patients: A systematic review. Clin. Nutr. 2018, 37, 1101-1113. [CrossRef] [PubMed]

7. Prado, C.M.; Lieffers, J.R.; McCargar, L.J.; Reiman, T.; Sawyer, M.B.; Martin, L.; Baracos, V.E. Prevalence and clinical implications of sarcopenic obesity in patients with solid tumours of the respiratory and gastrointestinal tracts: A population-based study. Lancet Oncol. 2008, 9, 629-635. [CrossRef]

8. Shachar, S.S.; Williams, G.R.; Muss, H.B.; Nishijima, T.F. Prognostic value of sarcopenia in adults with solid tumours: A meta-analysis and systematic review. Eur. J. Cancer 2016, 57, 58-67. [CrossRef] [PubMed]

9. Kazemi-Bajestani, S.M.R.; Mazurak, V.C.; Baracos, V. Computed tomography-defined muscle and fat wasting are associated with cancer clinical outcomes. Semin. Cell Dev. Biol. 2016, 54, 2-10. [CrossRef] [PubMed]

10. Mintziras, I.; Miligkos, M.; Waechter, S.; Manoharan, J.; Maurer, E.; Bartsch, D.K. Sarcopenia and sarcopenic obesity are significantly associated with poorer overall survival in patients with pancreatic cancer: Systematic review and meta-analysis. Int. J. Surg. 2018. [CrossRef] [PubMed]

11. Cruz-Jentoft, A.J.; Baeyens, J.P.; Bauer, J.M.; Boirie, Y.; Cederholm, T.; Landi, F.; Martin, F.C.; Michel, J.-P.; Rolland, Y.; Schneider, S.M.; et al. Sarcopenia: European consensus on definition and diagnosis: Report of the European Working Group on Sarcopenia in Older People. Age Ageing 2010, 39, 412-423. [CrossRef] [PubMed]

12. Argiles, J.M.; Busquets, S.; Stemmler, B.; Lopez-Soriano, F.J. Cachexia and sarcopenia: Mechanisms and potential targets for intervention. Curr. Opin. Pharmacol. 2015, 22, 100-106. [CrossRef] [PubMed]

13. Yoshida, T.; Delafontaine, P. Mechanisms of cachexia in chronic disease states. Am. J. Med Sci. 2015, 350, 250-256. [CrossRef] [PubMed]

14. Sadeghi, M.; Keshavarz-Fathi, M.; Baracos, V.; Arends, J.; Mahmoudi, M.; Rezaei, N. Cancer cachexia: Diagnosis, assessment, and treatment. Crit. Rev. Oncol./Hematol. 2018, 127, 91-104. [CrossRef] [PubMed]

15. Lucidi, C.; Lattanzi, B.; Di Gregorio, V.; Incicco, S.; D’ambrosio, D.; Venditti, M.; Riggio, O.; Merli, M. A low muscle mass increases mortality in compensated cirrhotic patients with sepsis. Liver Int. 2018, 38, 851-857. [CrossRef] [PubMed]

16. Shibahashi, K.; Sugiyama, K.; Kashiura, M.; Hamabe, Y. Decreasing skeletal muscle as a risk factor for mortality in elderly patients with sepsis: A retrospective cohort study. J. Intensive Care 2017, 5, 8. [CrossRef]

17. Ji, Y.; Cheng, B.; Xu, Z.; Ye, H.; Lu, W.; Luo, X.; Fu, S.; Fang, X. Impact of sarcopenic obesity on 30-day mortality in critically ill patients with intra-abdominal sepsis. J. Crit. Care 2018, 46, 50-54. [CrossRef] [PubMed] 
18. Martin, L.; Birdsell, L.; MacDonald, N.; Reiman, T.; Clandinin, M.T.; McCargar, L.J.; Murphy, R.; Ghosh, S.; Sawyer, M.B.; Baracos, V.E. Cancer cachexia in the age of obesity: Skeletal muscle depletion is a powerful prognostic factor, independent of body mass index. J. Clin. Oncol. 2013, 31, 1539-1547. [CrossRef]

19. Dellinger, R.P.; Levy, M.M.; Rhodes, A.; Annane, D.; Gerlach, H.; Opal, S.M.; Sevransky, J.E.; Sprung, C.L.; Douglas, I.S.; Jaeschke, R. Surviving Sepsis Campaign: International guidelines for management of severe sepsis and septic shock, 2012. Intensive Care Med. 2013, 39, 165-228. [CrossRef]

20. Casserly, B.; Phillips, G.S.; Schorr, C.; Dellinger, R.P.; Townsend, S.R.; Osborn, T.M.; Reinhart, K.; Selvakumar, N.; Levy, M.M. Lactate measurements in sepsis-induced tissue hypoperfusion: Results from the Surviving Sepsis Campaign database. Crit. Care Med. 2015, 43, 567-573. [CrossRef]

21. Chae, B.-R.; Kim, Y.-J.; Lee, Y.-S. Prognostic accuracy of the sequential organ failure assessment (SOFA) and quick SOFA for mortality in cancer patients with sepsis defined by systemic inflammatory response syndrome (SIRS). Support. Care Cancer 2019, 1-7. [CrossRef] [PubMed]

22. AsanJ-Morphometry. Available online: http://datasharing.aim-aicro.com/en/morphometry (accessed on 10 August 2019).

23. Yip, C.; Dinkel, C.; Mahajan, A.; Siddique, M.; Cook, G.J.; Goh, V. Imaging body composition in cancer patients: Visceral obesity, sarcopenia and sarcopenic obesity may impact on clinical outcome. Insights Imaging 2015, 6, 489-497. [CrossRef] [PubMed]

24. Organization, W.H. The Asia-Pacific Perspective: Redefining Obesity and Its Treatment; Health Communications Australia: Sydney, Australia, 2000.

25. Muscaritoli, M.; Anker, S.; Argiles, J.; Aversa, Z.; Bauer, J.; Biolo, G.; Boirie, Y.; Bosaeus, I.; Cederholm, T.; Costelli, P. Consensus definition of sarcopenia, cachexia and pre-cachexia: Joint document elaborated by Special Interest Groups (SIG)"cachexia-anorexia in chronic wasting diseases" and "nutrition in geriatrics". Clin. Nutr. 2010, 29, 154-159. [CrossRef] [PubMed]

26. Prado, C.M.; Purcell, S.A.; Alish, C.; Pereira, S.L.; Deutz, N.E.; Heyland, D.K.; Goodpaster, B.H.; Tappenden, K.A.; Heymsfield, S.B. Implications of low muscle mass across the continuum of care: A narrative review. Ann. Med. 2018, 50, 675-693. [CrossRef] [PubMed]

27. Purcell, S.; Elliott, S.; Baracos, V.; Chu, Q.; Prado, C. Key determinants of energy expenditure in cancer and implications for clinical practice. Eur. J. Clin. Nutr. 2016, 70, 1230. [CrossRef]

28. Reisinger, K.W.; van Vugt, J.L.; Tegels, J.J.; Snijders, C.; Hulsewé, K.W.; Hoofwijk, A.G.; Stoot, J.H.; Von Meyenfeldt, M.F.; Beets, G.L.; Derikx, J.P. Functional compromise reflected by sarcopenia, frailty, and nutritional depletion predicts adverse postoperative outcome after colorectal cancer surgery. Ann. Surg. 2015, 261, 345-352. [CrossRef]

29. Peterson, S.J.; Braunschweig, C.A. Prevalence of sarcopenia and associated outcomes in the clinical setting. Nutr. Clin. Pract. 2016, 31, 40-48. [CrossRef]

30. Martin, C.M.; Hill, A.D.; Burns, K.; Chen, L.M. Characteristics and outcomes for critically ill patients with prolonged intensive care unit stays. Crit. Care Med. 2005, 33, 1922-1927. [CrossRef]

31. Yoon, S.L.; Grundmann, O.; Williams, J.J.; Gordan, L.; George, T.J., Jr. Body composition changes differ by gender in stomach, colorectal, and biliary cancer patients with cachexia: Results from a pilot study. Cancer Med. 2018, 7, 3695-3703. [CrossRef]

32. Montalvo, R.N.; Counts, B.R.; Carson, J.A. Understanding sex differences in the regulation of cancer-induced muscle wasting. Curr. Opin. Support. Palliat. Care 2018, 12, 394-403. [CrossRef]

33. Blaak, E. Gender differences in fat metabolism. Curr. Opin. Clin. Nutr. Metab. Care 2001, 4, 499-502. [CrossRef] [PubMed]

34. Haizlip, K.; Harrison, B.; Leinwand, L. Sex-based differences in skeletal muscle kinetics and fiber-type composition. Physiology 2015, 30, 30-39. [CrossRef] [PubMed]

35. Bouffard, J.; Yang, C.; Begon, M.; Côté, J. Sex differences in kinematic adaptations to muscle fatigue induced by repetitive upper limb movements. Biol. Sex Differ. 2018, 9, 17. [CrossRef] [PubMed]

36. Ciciliot, S.; Rossi, A.C.; Dyar, K.A.; Blaauw, B.; Schiaffino, S. Muscle type and fiber type specificity in muscle wasting. Int. J. Biochem. Cell Biol. 2013, 45, 2191-2199. [CrossRef] [PubMed]

37. Schiaffino, S.; Reggiani, C. Fiber types in mammalian skeletal muscles. Physiol. Rev. 2011, 91, $1447-1531$. [CrossRef] [PubMed] 
38. Stephens, N.A.; Gray, C.; MacDonald, A.J.; Tan, B.H.; Gallagher, I.J.; Skipworth, R.J.; Ross, J.A.; Fearon, K.C.; Greig, C.A. Sexual dimorphism modulates the impact of cancer cachexia on lower limb muscle mass and function. Clin. Nutr. 2012, 31, 499-505. [CrossRef] [PubMed]

39. Choi, Y.; Oh, D.-Y.; Kim, T.-Y.; Lee, K.-H.; Han, S.-W.; Im, S.-A.; Kim, T.-Y.; Bang, Y.-J. Skeletal muscle depletion predicts the prognosis of patients with advanced pancreatic cancer undergoing palliative chemotherapy, independent of body mass index. PLoS ONE 2015, 10, e0139749. [CrossRef] [PubMed]

40. Azoulay, E.; Schellongowski, P.; Darmon, M.; Bauer, P.R.; Benoit, D.; Depuydt, P.; Divatia, J.V.; Lemiale, V.; van Vliet, M.; Meert, A.-P. The Intensive Care Medicine research agenda on critically ill oncology and hematology patients. Intensive Care Med. 2017, 43, 1366-1382. [CrossRef]

41. Shrime, M.G.; Ferket, B.S.; Scott, D.J.; Lee, J.; Barragan-Bradford, D.; Pollard, T.; Arabi, Y.M.; Al-Dorzi, H.M.; Baron, R.M.; Hunink, M.M. Time-limited trials of intensive care for critically ill patients with cancer: How long is long enough? JAMA Oncol. 2016, 2, 76-83. [CrossRef] [PubMed]

42. Taaffe, D.R.; Cauley, J.A.; Danielson, M.; Nevitt, M.C.; Lang, T.F.; Bauer, D.C.; Harris, T.B. Race and sex effects on the association between muscle strength, soft tissue, and bone mineral density in healthy elders: The Health, Aging, and Body Composition Study. J. Bone Miner. Res. 2001, 16, 1343-1352. [CrossRef]

(C) 2019 by the authors. Licensee MDPI, Basel, Switzerland. This article is an open access article distributed under the terms and conditions of the Creative Commons Attribution (CC BY) license (http://creativecommons.org/licenses/by/4.0/). 